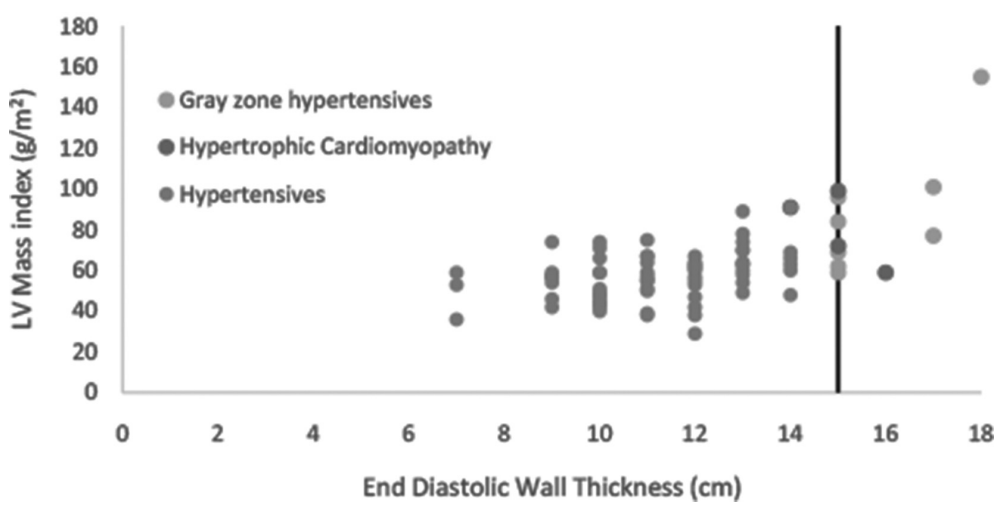

Abstract 99 Figure 1 LV Mass/EDWT Relationship in Hypertensive and HCM patients

diagnosis.19 individuals were referred on to the dedicated inherited cardiac conditions clinic for further evaluation. Four patients expressed a definitive LV phenotype and were diagnosed with HCM. CMR parameters were compared in three groups: Hypertensive (HTN), grey zone Hypertensive (GZH) and HCM. See figure 1 and table 1.

Results CMR demonstrated end diastolic wall thickness (EDWT) $>11 \mathrm{~mm}$ in $50 \%$ of hypertensives. $73 \%$ of the referred patients were $\mathrm{AC}$ and all $4 \mathrm{HCM}$ patients were also AC. All referrals demonstrated EDWTs $14 \mathrm{~mm}, 9$ (47\%) demonstrated late gadolinium enhancement of which $3(16 \%)$ had HCM. Three had asymmetrical septal hypertrophy - 2 were in the HCM cohort and one underwent endomyocardial biopsy confirming HTN. Left ventricular mass index (LVMI) was significantly higher in GZH compared to HTN $(\mathrm{p}<0.0001)$ and in HCM compared to HTN $(\mathrm{p}=0.0004)$. EDWT was significantly greater in GZH compared to HTN $(p<0.0001)$ and in HCM compared to HTN $(p=0.0002)$. There was no significant difference in these parameters between GZH and HCM. See figure 1 and table 1.

Conclusion This study reports a $4 \%$ prevalence of HCM among hypertensive patients $-20 \times$ greater than in the general population - which would not be diagnosed using echo alone. Screening hypertensive individuals with CMR is not yet routine but we advocate its use in these individuals especially in those of AC ethncitiy and in those in the "grey zone", to identify undiagnosed HCM, which has significant implications for lifestyle modification and family screening.

Conflict of Interest none

\section{GENDER DIFFERENCES IN EXPERIENCES OF DISCRIMINATION, SEXUAL HARASSMENT AND BARRIERS TO CAREER ADVANCEMENT AMONG CARDIOLOGISTS IN THE UK}

${ }^{1}$ Shareen Jaijee*, ${ }^{2}$ Caroline Kamau. ${ }^{1} /$ mperial College Health Network Trust; ${ }^{2}$ Birkbeck University

\subsection{6/heartjnl-2019-BCS.97}

Introduction Female physicians face many hurdles, starting from medical school through their careers including a disparity in pay, professional advancement, barriers to work-life balance gender discrimination and sexual harassment. Limited research has been carried out in the UK to determine whether women Cardiologists face similar issues.
Methods A questionnaire was developed from previous studies carried out in the US and from other validated questionnaires. An online survey platform was used to distribute the survey between March and May 2018 to male and female consultant cardiologists in the UK. Ethical approval was obtained from Birkbeck, University of London. Comparisons between men and women were carried out using the chi square test, and tested for pairwise comparisons with a Bonferroni correction for multiple analyses. A two-sided $p$ value of $<0.05$ was considered statistically significant.

Results 174 cardiologists completed the survey. Women were more likely to be single $(1.5 \%$ vs $9.5 \%)$ and men married $(94.7 \%$ vs $78.6 \%)(p=0.010)$. Men were more likely to have children compared to women $(91.7 \%$ vs $78.6 \%, \mathrm{p}=0.020)$. More men had either full time $(37.9 \%$ vs $0 \%, \mathrm{p}<0.0001)$ or part time $(40.2 \%$ vs $21.4 \%, \mathrm{p}=0.028)$ spousal care for their children. Women spend significantly more hours on household work than men ( $\mathrm{p}=<0.0001$ ). 29.9\% of the overall UK Cardiology workforce has experienced discrimination, with $61.9 \%$ of women reporting discrimination vs $19.7 \%$ of men $(<0.0001)$. More women reported experiencing discrimination based on gender and parenting responsibilities $(2.0 \%$ vs $31.0 \%$ and $2.3 \%$ vs $52.4 \%$ respectively, p <0.0001). More women have experienced unwanted sexual comments, attention or advances from a superior or colleagues, compared to men $(35.7 \%$ vs. $6.1 \%$ p $<0.0001)$. More women compared to men perceived gender biases or obstacles to the career success or faculty by gender in their environment $(12.1 \%$ vs $47.6 \%, \mathrm{p}<0.0001)$ Furthermore, more women felt they had been left out of opportunities for professional advancement based on gender, (2.3\% vs 33.3\%). $42.8 \%$ of women Cardiologists report their career advancement was lower compared to $9 \%$ men $(\mathrm{p}<0.0001)$. More than half $(52.3 \%)$ of all cardiologists agreed that career prospects are lower for women in all cardiology sub-specialities. The majority of women agree with this statement $(44 \%$ vs $78.6 \%, \mathrm{p}<0.0001)$ while the majority of men believe that it is about the same $(51.5 \%$ vs $21.4 \%)$ and a small proportion believing it is higher (4.6\% vs $0.0 \%)$ Conclusion Women cardiologists in the UK face discrimination, sexual harassment and gender bias in professional advancement. This study identifies key areas where solutions should be focussed and highlights that further research is required. In this era of \#MeToo, there is no better time for the organisations that support UK Cardiologists, to seriously implement interventions that will improve the working conditions for women and men, and continue to sustain the high job satisfaction, in Cardiology. 


\section{Conflict of Interest None}

\section{BLOOD PRESSURE AND CAPILLARY MICROCIRCULATION AT BIRTH IN INFANTS BORN TO MOTHERS WITH A HYPERTENSIVE DISORDER OF PREGNANCY}

\footnotetext{
1,2 Muti Goloba*, ${ }^{1}$ Rajendra Raghuraman*, 'uzma Khan* ${ }^{1}$ Nansi Botros, ${ }^{1}$ Monique Klein, ${ }^{1}$ Amelia Brown, ${ }^{3}$ Donovan Duffy, ${ }^{4}$ Nick Anim-Nyame, ${ }^{5}$ Duolao Wang, ${ }^{6}$ Isaac Manyonda, 1,2Tarek F Antonios. 'Molecular and Clinical Sciences Research Institute, St George's, University of London ${ }^{2}$ Blood Pressure Unit ${ }^{3}$ Neonatal Unit, and Obstetrics \& Gynaecology Department, St George's University Hospitals NHS Foundation Trust, London ${ }^{4}$ Obstetrics \& Gynaecology Department, Kingston Hospital NHS Foundation Trust, London ${ }^{5}$ Department of Clinical Sciences, Liverpool School of Tropical Medicine, Liverpool, UK
}

10.1136/heartjnl-2019-BCS.98

Background Hypertensive disorders of pregnancy (HDP) increase the risk of future cardiovascular disease including hypertension, stroke and diabetes mellitus not only in the affected women but in their offspring as well. Microcirculatory abnormalities and in particular capillary rarefaction (CR) are a hallmark of essential hypertension. We have previously reported that $\mathrm{CR}$ is found in individuals with established and borderline hypertension, and in normotensive individuals with a familial predisposition to hypertension. In a previous pilot study, we found that infants born pre-term to mothers with an $\mathrm{HDP}$ have significant $\mathrm{CR}$ at birth when compared to infants of normotensive mothers.

Methods In this BHF funded research, we studied 110 infants born to mothers with an HDP (87 were born with a normal birth weight (NBW) and 23 had low birth weight (LBW) and compared them to 284 NBW infants born at term to normotensive mothers (control group). We used intravital capillary microscopy to measure basal i.e. functional (BCD) and maximal i.e. structural (MCD) skin capillary densities according to a well-validated protocol. We used the Welch Allyn VSM 300 TM monitor to measure the infants' BP. All infants were studied at birth, 3 months, 6 months and 12 months. We report here the results at birth.

Results Systolic BP was significantly higher in LBW $(81.04 \pm 9.99 \mathrm{mmHg}, \mathrm{p}=0.013)$ and NBW $(76.91 \pm 11.64 \mathrm{mmHg}$, $\mathrm{p}=0.043$ ) infants of HDP mothers compared to infants of normotensive mothers $(73.69 \pm 10.71 \mathrm{mmHg})$. There were no significant differences in diastolic BP. Both LBW and NBW infants born to HDP mothers had significantly higher BCD (mean difference of $13.66,95 \%$ CI 6.82 to 20.51 cap/field; $\mathrm{p}<0.0001$ ) and (mean difference of 5.40 , 95\%CI 1.72 to 9.08 cap/field; $p=0.004)$ respectively compared to control group). They also had higher MCD (mean difference of 10.32, 95\%CI 2.84 to 17.81 cap/field; $\mathrm{p}=0.007$ ) and (mean difference of 3.87 , 95\%CI 0.19 to 7.94 cap/field; $p=0.062$ ) respectively compared to control group.

Conclusion Infants born to mothers with an HDP have significantly higher systolic BP at birth compared to infants of normotensive mothers. Furthermore, LBW infants of HDP mothers have a significantly higher $\mathrm{BCD}$ and $\mathrm{MCD}$ compared to NBW of normotensive mothers. Further follow-up studies of these infants are required to investigate the role of the microcirculation in the pathogenesis of essential hypertension.

Acknowledgement We thank the BHF for funding this research (PG/13/87/30550)

Conflict of Interest None

\section{THE IMPACT OF GENDER AND MARITAL STATUS ON LONG TERM MORTALITY IN PATIENTS WITH CARDIOVASCULAR DISEASE: INSIGHTS UTILISING BIG DATA FROM THE ACALM STUDY}

${ }^{1}$ Rahul Potluri, ${ }^{2}$ Ahmed Qashou*, ${ }^{3}$ Paul Carter, ${ }^{2}$ Billal Patel, ${ }^{2}$ Ranjit More, ${ }^{2}$ Deepthi Lavu. ${ }^{1}$ Blackpool Teaching Hospitals; ${ }^{2}$ Blackpool Teaching Hospital NHS Foundation Trust; ${ }^{3}$ ACALM Study Unit

\subsection{6/heartjnl-2019-BCS.99}

Background Married patients with Acute Coronary Syndrome (ACS) have significantly improved mortality compared to single patients while the worst outcomes are seen among divorcees. The impact of gender, marital status and outcomes in patients with cardiovascular disease has been poorly studied. Using big data, we addressed this further by studying patients with ACS, Heart Failure (HF) and Atrial Fibrillation (AF).

Methods Anonymous information on patients with ACS, HF and $\mathrm{AF}$, including comorbidities, was obtained from UK

Abstract 102 Table 1 Cox regression comparing mortality of males vs females in patients with ACS, HF and AF

\begin{tabular}{|c|c|c|c|c|c|c|c|c|c|}
\hline \multicolumn{10}{|c|}{ Cox regression comparing mortality of males vs females in patients with ACS, HF and AF } \\
\hline & \multicolumn{3}{|c|}{ Acute Coronary Syndrome } & \multicolumn{3}{|c|}{ Heart Failure } & \multicolumn{3}{|c|}{ Atrial Fibrillation } \\
\hline $\begin{array}{l}\text { Marital } \\
\text { Status }\end{array}$ & $\begin{array}{l}\text { Odds } \\
\text { Ratio }\end{array}$ & $\begin{array}{l}95 \% \\
\text { C.I }\end{array}$ & $\begin{array}{l}\mathbf{P} \\
\text { Value }\end{array}$ & $\begin{array}{l}\text { Odds } \\
\text { Ratio }\end{array}$ & $\begin{array}{l}95 \% \\
\text { C.I }\end{array}$ & $\begin{array}{l}\mathbf{P} \\
\text { Value } \\
\end{array}$ & $\begin{array}{l}\text { Odds } \\
\text { Ratio }\end{array}$ & $\begin{array}{l}95 \% \\
\text { C.I }\end{array}$ & $\begin{array}{l}\mathbf{P} \\
\text { Value }\end{array}$ \\
\hline Single & 0.96 & $\begin{array}{l}0.82- \\
1.13\end{array}$ & 0.65 & 0.87 & $\begin{array}{l}0.79- \\
0.97\end{array}$ & 0.01 & 0.99 & $\begin{array}{l}0.90- \\
1.10\end{array}$ & 0.89 \\
\hline Married & 0.98 & $\begin{array}{l}0.92- \\
1.05\end{array}$ & 0.59 & 1.03 & $\begin{array}{l}0.98- \\
1.08\end{array}$ & 0.16 & 1.06 & $\begin{array}{l}1.02- \\
1.11\end{array}$ & $<0.01$ \\
\hline Divorced & 1.06 & $\begin{array}{l}0.97- \\
1.16\end{array}$ & 0.20 & 1.04 & $\begin{array}{l}0.97- \\
1.11\end{array}$ & 0.24 & 1.14 & $\begin{array}{l}1.07- \\
1.22\end{array}$ & $<0.01$ \\
\hline Widowed & 1.11 & $\begin{array}{l}1.02- \\
1.21\end{array}$ & 0.02 & 1.10 & $\begin{array}{l}1.04- \\
1.16\end{array}$ & $<0.01$ & 1.13 & $\begin{array}{l}1.07- \\
1.19\end{array}$ & $<0.01$ \\
\hline $\begin{array}{l}\text { Legally } \\
\text { Separated }\end{array}$ & 1.25 & $\begin{array}{l}0.72- \\
2.16\end{array}$ & 0.42 & 0.87 & $\begin{array}{l}0.62- \\
1.22\end{array}$ & 0.41 & 0.89 & $\begin{array}{l}0.61- \\
1.30\end{array}$ & 0.54 \\
\hline
\end{tabular}

